\title{
Diário de bordo, de Cecília Meireles, ilustrado por Fernando Correia Dias: correspondências artísticas e gênese da viagem na obra ceciliana
}

"Diário de bordo", by Cecília Meireles, illustrated by Fernando Correia Dias: artistic correspondence and genesis of the trip in the work of Cecília Meireles

\section{Luís Antônio Contatori Romano ${ }^{1}$}

MEIRELES, Cecília. Diário de bordo. Ilustrações de Fernando Correia Dias. São Paulo: Global, 2015.

Diário de bordo, de Cecília Meireles, lançado pela Editora Global em 20I5, seduz de imediato pela beleza da cuidadosa edição, em papel couché reflex, que contribui para destacar as reproduções fotográficas de ilustrações criadas pelo artista plástico Fernando Correia Dias, primeiro marido da poeta. Ao nos determos no texto, encontramos a reunião das primeiras crônicas de viagem de Cecília Meireles, escritas diariamente durante a travessia marítima do Rio de Janeiro a Lisboa a bordo do navio Cuyabá, entre 20 de setembro e I2 de outubro de I934, em companhia de Correia Dias. São 22 crônicas que registram impressões da luz, do mar, dos passageiros e da tripulação, das paisagens que a poeta vê ao largo, das cidades em que o navio atraca... textos que sempre têm correspondências em ilustrações feitas por Correia Dias durante a viagem, empregando a técnica de pintura direta alla prima, bastante difundida entre os pintores impressionistas.

ROMANO, Luís Antônio Contatori. Diário de bordo, de Cecília Meireles, ilustrado por Fernando Correia Dias: correspondências artísticas e gênese da viagem na obra ceciliana. Revista do Instituto de Estudos Brasileiros, Brasil, n. 64, p. 325-335, ago. 2016.

DOI: http://dx.doi.org/Io.II6o6/issn.23I6-90IX.voi64p325-335

I Universidade Federal do Sul e Sudeste do Pará (Unifesspa, Marabá, PA, Brasil) e CNPq (pesquisador produtividade). 
Nesses textos, encontramos, em gênese, registros de impressões que reaparecerão na obra posterior de Cecília Meireles, especialmente na poesia de Viagem, de I938, e de Mar absoluto, de I945, e também, é claro, na prosa-poética de crônicas de outras viagens, que a poeta realizará entre as décadas de I940 e I960. Já estão presentes em Diário de bordo: o mar como metáfora do infinito em oposição à transitoriedade da vida, passível de reinvenção estética; pensamentos sobre a "arte de viajar" e o desejo de ser "marinheira", ambos ligando-se a uma espécie de nostalgia das origens familiares, além de interesses por temas da cultura popular, recorrentes em suas crônicas de educação, escritas entre as décadas de I930 e I940, em textos publicados na revista Travel in Brazil, entre I94I e I942, e no livro Artes populares, da década de I950. A essa riqueza intratextual que Diário de bordo revela, une-se certo recurso intertextual, também tão marcante nas crônicas de viagem posteriores - textos que são verdadeiros hipertextos avant la lettre. Assim, além da íntima correspondência entre as pinturas em palavras de Cecília Meireles e as ilustrações em pincel e tinta de Fernando Correia Dias, ambas as expressões permitem aproximações com artes plásticas diversas. Há, por exemplo, comparações manifestas entre o que Cecília vê na paisagem marinha e a pintura oriental e a porcelana dinamarquesa. Mas o atento leitor-viajante também poderá tecer relações entre as correspondências artísticas Cecília-Fernando com obras de outros pintores.

Em 1934, Cecília Meireles e Correia Dias colaboravam no diário carioca A nação, destino das crônicas, ilustradas pelo marido, que Cecília enviava, por correio, durante as escalas do navio. A travessia significava para Correia Dias uma possibilidade de reencontro com a terra natal depois de vinte anos radicado no Brasil. Também para Cecília era uma viagem de "reencontro" sentimental com suas origens portuguesas.

Em Portugal, permaneceram por três meses, onde, a convite da amiga Fernanda de Castro, esposa de António Ferro, então diretor da Secretaria de Propaganda Nacional, do governo Salazar, a poeta proferiu conferências. A mais conhecida, realizada em I7 de dezembro de I934, foi "Samba, batuque e macumba", ricamente ilustrada pela própria poeta, sendo publicada no ano seguinte como separata da revista Mundo português. Durante essa estada de três meses, estava incumbida de fazer entrevistas e reportagens para $A$ nação e outros jornais cariocas e paulistas nos quais colaborava. O casal retornou ao Brasil a bordo do navio Bagé, também do Lloyd Brasileiro, como o Cuyabá, chegando ao Rio de Janeiro em I2 de janeiro de I935.

Na edição do Diário de bordo, além das crônicas de Cecília, com as ilustrações de Correia Dias, há também reproduções de antigas fotografias do casal e de páginas do "Diário de bordo", publicado no jornal A nação em I934, que enriquecem o valor documental da obra e contribuem para transmitir certo clima nostálgico, abrindo-se para a fantasia do leitor, tão ao gosto dos textos de viagem cecilianos. Esse rico material literário, pictórico e fotográfico é precedido de uma introdução escrita pelo neto da poeta e curador da edição, Alexandre Carlos Teixeira, além de textos de Alberto da Costa e Silva e de Jussara Pimenta, que também redige o posfácio. Não somente pela qualidade da edição, que, por si só, valoriza as ilustrações, evidencia-se, nesses textos introdutórios, certa intenção de projetar luz sobre o trabalho artístico de Fernando Correia Dias, um tanto quanto esquecido e do qual praticamente não há referências evidentes em outras obras de Cecília Meireles. Alexandre Teixeira e 
Jussara Pimenta procuram realçar as possíveis influências desse múltiplo artista português na formação literária da poeta.

Pimenta salienta que Correia Dias trabalhou como ilustrador para as revistas do grupo Festa, liderado por Tasso da Silveira e Andrade Muricy, que frequentavam a residência do casal no Rio de Janeiro. Além disso, antes de emigrar para o Brasil, Correia Dias havia trabalhado em revistas literárias portuguesas com Fernando Pessoa, Almada Negreiros, entre outros modernistas, sugerindo-se que foi através do primeiro marido que Cecília teria se tornado, talvez, a primeira leitora de relevância da poesia de Pessoa no Brasil, ainda na década de I920. Alberto da Costa e Silva salienta que, a partir dessa viagem a Portugal, as afinidades com o tema do mar se instalarão definitivamente na poesia de Cecília Meireles como paisagem e símbolo.

Na crônica de 26 de setembro de I934, Cecília relata um dia de navegação entre Salvador e Recife. Depois de contar, em tom irônico, sobre as conversas femininas corriqueiras nas cadeiras do convés do navio, a crônica termina com impressões das variações de luz que incidem sobre a paisagem marinha ao longo do dia:

Pela manhã, despontam céus rosados, com nuvens de gaze trêmula, que o sol vai desfolhando, ao surgir. O mar é ainda todo feito de sombra, com o resto da noite adormecido no fundo.

Depois, vai tudo brilhando e ganhando transparência e cor. O meio-dia deslumbra. A água dissolve safiras e diamantes. O céu tem uma nitidez de porcelana. E o vento vai levando a fumaça do navio, que tanto se desdobra no céu como no reflexo das ondas. Começa, então, a refrescar no boroeste, e em bombordo o convés se enche de sol.

O crepúsculo tem sido vivo de cores e rico de nuvens. Um instante o sol fica rente às águas, invertido nelas. Depois cai para dentro. Some-se, como se o mar o bebesse.

Penso na impressão dos homens primitivos diante desse desaparecimento da luz. E imagino que a primeira viagem pelas águas talvez fosse para descobrir onde ao certo morava o sol $^{2}$.

Essa crônica é ilustrada por duas notáveis pinturas de Correia Dias, em harmonia com as impressões que a poeta pinta com palavras e com seu estado de alma. Uma delas corresponde à imagem do amanhecer sobre o mar3. Correia Dias pinta o sol emergindo do mar azul, mas "ainda todo feito de sombra", sugerindo "o resto da noite”. O céu se ilumina de cores, mas, na pintura, de grandes pinceladas, são mais fortes e tensas que os tons rosados descritos por Cecília, são vermelhos, amarelos e verdes, não permitindo entrever as "nuvens de gaze trêmula", vislumbradas pela poeta. A visão do amanhecer sobre o mar, descrita na crônica, pode sugerir Monet, talvez a tela Impressão, sol nascente, de I874, embora nesta tenhamos impressões de um

2 MEIRELES, Cecília. Diário de bordo. Ilustrações de Fernando Correia Dias. São Paulo: Global, 20I5, p. 67.

3 Ibidem, p. 66-67. 
instante posterior àquele registrado pela poeta, pois o sol já vai um pouco alto e seu reflexo começa a se sobrepor às sombras noturnas do mar. Já na pintura de Correia Dias sente-se uma certa intensidade de cores, sugerindo um efeito de dramaticidade, aproximando-o, talvez, mais de William Turner que de Claude Monet.

Em momento mais avançado, em 5 de outubro, após três dias de navegação, o Cuyabá passa pelas ilhas de Maio e Boa Vista, no arquipélago de Cabo Verde. Cecília Meireles registra um pensamento que revela solidão, a pequenez e a efemeridade dos sofrimentos humanos diante da imensidão de águas e da permanência das terras:

É uma estranha sensação, esta de ficar à amurada de um navio, depois de longos dias de águas desertas, esperando o aparecimento de um pedaço de terra que não nos verá, diante da qual passaremos com o nosso mistério, como se não existíssemos, ficando, para depois de nós, para além da nossa vida, com a sua duração insensível sobrevivendo ao prazer e à dor que agravaram a nossa angústia de efêmeros4.

Outra ilustração de Correia Dias ${ }^{5}$ que acompanha a crônica de 26 de setembro, e também está na capa da edição de Diário de bordo, mostra uma mulher no canto esquerdo da tela, de costas, toda coberta de roupas escuras, debruçada no parapeito do convés do navio a contemplar a paisagem, terras montanhosas ao longe, em nuances escuras que se intensificam no canto direito da tela, correspondendo, possivelmente, ao ponto a que se dirige o olhar da personagem feminina. Paisagem que poderia também ser a que Cecília contempla ao largo das ilhas do arquipélago de Cabo Verde. Na pintura, Correia Dias harmoniza simetricamente os tons mais escuros da tela: as roupas da personagem contemplativa, de costas para o espectador, e a paisagem montanhosa, do outro lado das águas marinhas. Cena que pode lembrar Mulher à janela em Figueres, de Salvador Dalí (I926). No entanto, o volume e o delineamento da personagem não têm a nitidez e a sensualidade que encontramos na representação da modelo Ana Maria Dalí, que parece ganhar concretude na tela. A Cecília de Correia Dias é quase uma sombra, é lateral a uma paisagem maior que ela, enquanto a de Dalí está apenas levemente deslocada do centro, é nítida, luminosa e sensual, destaca-se do cenário e sugere movimento calmo e vivacidade através das ondulações dos cabelos, da posição da perna direita, além da sugestão do vento a balançar as cortinas e o vestido de tecido leve, movimento em harmonia com o ritmo das ondas de um mar calmo. O leve deslocamento de Ana Maria Dalí do centro do quadro permite que ela contemple a paisagem externa à janela, que, pelo reflexo no vidro, percebe-se ser dominada por uma povoação de construções brancas. Assim, volume, delineamento, movimento, nitidez e até o deslocamento contribuem para criar certa ilusão de concretude e realidade.

Na pintura de Correia Dias, embora haja alguma sugestão de movimento nas ondas do mar e na parte inferior do pesado vestido deslocado pelo vento, a personagem, completamente coberta com roupas pesadas e escuras, é lateral à paisagem vista: mar, praia, vegetação e montanhas, destituída de quaisquer marcas humanas.

4 Ibidem, p. I27-I28.

5 In: MEIRELES, Cecília. Diário de bordo, op. cit., 20I5, p. 63. 
Essa paisagem parece absorvê-la e apequená-la em sua solidão. Por isso, talvez a pudéssemos aproximar da mulher do quadro Automat, de Edward Hopper (I927). Deixemos de lado as correntes, e evidentes, interpretações que consideram o quadro de Hopper uma representação da solidão humana na era da modernidade burguesa e associam o título não somente ao cenário como também à rigidez corporal da personagem, pensemos apenas em sua solidão e ensimesmamento. A Cecília pintada por Correia Dias, solitária e de costas para o passadiço do navio, olha a paisagem como se estivesse voltada para si mesma, como alguém indevassável, o que parece reforçado pelas roupas pesadas e escuras que a encobrem. Em Hopper, o restaurante vazio, envidraçado, e a ausência de marcas humanas através do vidro, para o qual a personagem feminina dá as costas, intensificam a sensação de autofechamento.

Assim, paradoxalmente, a personagem feminina de Correia Dias parece condensar a calma contemplação da Mulher à janela em Figueres, de Dalí, sentindo-se absorvida pelo mundo natural e deserto que olha, com o autofechamento da moça solitária sentada à lanchonete, de Hopper. Nesta as roupas escuras e o fundo escuro, embora de vidro, contrastam com a pele branca da mulher. Seus lábios vermelhos, em harmonia com o cesto de frutas, centro do quadro, em relação ao qual ela está levemente à direita, podem sugerir um sentimento de nostalgia de uma natureza perdida. A Cecília, embora lateral, parece imersa na paisagem deserta e natural que contempla, em sombria correspondência com ela.

Não estão ausentes dos registros de viagem de Cecília Meireles os trabalhadores, a literatura popular, as migrações humanas, que aproximam a poeta de temas modernistas. Na manhã do dia 28 de setembro, o Cuyabá está ancorado em Recife, e Cecília assiste a um carregamento de carvão:

Torsos negros e bronzeados dos estivadores de Recife, indo e vindo, curvandose e reerguendo-se entre baldes e pás nas chatas onde o carvão brilha que nem diamante negro - nunca sabereis que fostes, um momento, na vossa vida, o imenso deslumbramento de uns olhos silenciosos, perdidos a contemplar-vos do alto de um tombadilho! Não sabereis que fostes, na vossa humildade, uma obra de arte completa, de linha, de volume, de movimento e de cor, junto às águas oleosas, moles e azeitonadas nas proximidades do navio, - e logo diluindo-se em transparências azuis e em verde veronese sob a leveza dos pequenos barcos de velas redondas e claras! ${ }^{6}$

Descrição que lembra a tela Mestiço, de Portinari, também datada de I934. O cenário de Portinari é o campo, e o trabalhador mestiço dele se destaca pelo volume e pelos traços firmes, quase sensuais, em pose, a sugerir uma estátua em que o homem comum substitui heróis, reis ou deuses como modelo. Em Cecília, o cenário é o porto, e os estivadores são vistos em movimento, também estão presentes o volume e o delineamento dos torsos negros, também sensuais, que se elevam do cenário. $\mathrm{O}$ homem negro e suas tradições culturais, como já mencionado, serão temas de uma de suas conferências em Portugal, e Portinari reaparecerá, no início da década de I940, como tema de um dos artigos, escrito por Mário de Andrade, para a revista

6 MEIRELES, Cecília. Diário de bordo, op. cit., 20I5, p. 80. 
Travel in Brazil, que Cecília editará para o Departamento de Imprensa e Propaganda do governo Vargas.

Na crônica de 29 de setembro, Cecília revela entreter-se com leituras de poesia popular, literatura de cordel comprada na Bahia e em Pernambuco. E em 3 de outubro, ela descobre, na popa do Cuyabá, os repatriados, imigrantes portugueses que, frustrados em suas esperanças de fazer a América, retornavam à terra de origem, mais miseráveis do que quando de lá saíram. No entanto, são capazes de entreter-se com suas cantorias e instrumentos musicais. Deles, Correia Dias faz uma série de ilustrações, e Cecília transcreve fragmentos de cantigas. Assim a poeta inicia o registro de impressões dessa descoberta humana entre os passageiros da terceira classe:

Quando se chega à popa, de onde se percebe o cheiro acre da grande carga de cacau que o navio transporta, encontram-se os passageiros de terceira classe vencidos de preguiça, estendidos em cadeiras de lona ou sentados por onde podem, procurando brincar ainda, sob o imenso calor, com cantigas ao desafio, música de gaita, e alguma gargalhada rústica rematando o gracejo sussurrado?

Em 30 de setembro, o Cuyabá passa ao largo de Fernando de Noronha. Depois de uma descrição de impressões marítimas, Cecília conclui com uma reflexão sobre o viajar: "E quem souber viajar preservando das tentações da superficialidade as virtudes contemplativas que, por acaso, possua, terá realizado uma experiência espiritual que dificilmente se conseguiria noutras condições”.

Importância que atribui à viagem como enriquecimento espiritual, conhecimento de si através do outro e de outras paragens, que se desenvolverá a partir das viagens que a poeta realizará, sobretudo, na década de I950, e cujos registros em crônicas contêm uma verdadeira teoria sobre a arte de viajar. Em "Uma hora em San Gimignano”, de I953, Cecília testemunha sua breve passagem por essa pequena cidade medieval da Toscana, mas que parece ter durado todo um dia, tal a intensidade da vivência psicológica que transmite. Cecília assim procura definir a arte de viajar:

A arte de viajar é uma arte de admirar, uma arte de amar. É ir em peregrinação, participando intensamente de coisas, de fatos, de vidas com as quais nos correspondemos desde sempre e para sempre. É estar constantemente emocionado, - e nem sempre alegre, mas, ao contrário, muitas vezes triste, de um sofrimento sem fim, porque a solidariedade humana custa, a cada um de nós, algum profundo despedaçamento?.

Tema que insiste em retornar nesse Diário de bordo é o da contemplação do mar como paisagem e símbolo do infinito em oposição à efemeridade e à pequenez do humano, que às vezes culmina no desejo expresso pela poeta de ser "marinheira",

7 Ibidem, p. II9.

8 Ibidem, p. 97.

9 Idem, Crônicas de viagem - 2. Rio de Janeiro: Nova Fronteira, I999, p. 6I. 
metáfora da possibilidade de escapar à temporalidade da existência ou de meio de retorno às origens das histórias familiares e sentimentais em Portugal, especialmente nos Açores, que ela tematizará na década de I950 como Ilha do Nanja em quatro crônicas. Assim, em 2 de outubro, quando o navio sai definitivamente da costa brasileira e se inicia um período de três dias até a aproximação do arquipélago de Cabo Verde, as lembranças de Vitória, Salvador, Recife, as passagens ao largo de Fernando de Noronha e dos rochedos de São Pedro e São Paulo vão virando saudades:

A grande ação do mar é o desprendimento a que nos obriga. Os problemas da terra perdem o sentido, quando se está a bordo. O mar despreza a realidade humana. Para que viver? Para que pensar? Para que fazer alguma coisa, no centro destas águas enormes, entregues ao seu destino cósmico, muito maior que o nosso? Antes de nós viveram estas águas infatigáveis, que em seus flancos sustentam e condensam torrentes de ocultas vidas. Muito depois de nós continuarão elas a respirar a noite e o dia, subindo e baixando, perdendo-se em tênue espuma, recuperando-se em imenso cristal. Comparada com a sua, nossa duração é inexpressiva e melancólica: - então, por que se fez necessário que aparecêssemos? tudo parecia mais perfeito, sem nós.... ${ }^{\mathrm{To}}$.

O pensamento sobre a insignificância do humano frente às águas marinhas reaparece, em perspectiva invertida, na crônica “Avião", de I952. Aqui o infinito é o céu, e o humano e seus frágeis artefatos encontram sua imagem na volatilidade das nuvens que se unem ou que parecem solitárias desintegrando-se irremediável e lentamente, como aquelas "nuvens de gaze trêmula" que se desfolham ao sol, que a poeta observa durante a travessia marítima:

A terra ficou subitamente muito longe. Naquele abismo vertical, a sombra do avião é do tamanho de um automóvel, de um sapato, de um lápis.O mundo do viajante é acima das florestas e das montanhas. Passam por ele as nuvens como outra humanidade. As grandes nuvens que se reúnem em assembleias brancas e cinzentas; as pequenas nuvens que passeiam de mãos dadas; as nuvens solitárias que lentamente elaboram a sua desintegração ${ }^{\text {II }}$.

O balançar do navio parece, em nenhum momento, incomodar a poeta-viajante, que revela o gosto pela marinhagem nessa anotação de 6 de outubro: "Se eu lhe dissesse que gostaria de viajar num navio de vela... num barquinho solitário, afundando e subindo por vales e monte de água... Se eu lhe dissesse que gostaria mesmo de viajar dentro de uma baleia...” ${ }^{\text {ז2 }}$

No dia 8 de outubro, Cecília está na expectativa da aproximação de Fuerte Ventura, nas Ilhas Canárias, e então explicita o desejo de ser “marinheira”:

\footnotetext{
IO Idem, Diário de bordo, op. cit., 20I5, p. II5.

II Idem. Crônicas de viagem - I. Rio de Janeiro: Nova Fronteira, I998.

I2 Idem. Diário de bordo, op. cit., 20I5, p. I37.
} 
Terei nascido para descobrimentos? Este sangue dos meus avós navegadores terá conservado tão palpitante a loucura deslumbrada de arrancar com os olhos as terras que dormem no ventre dos horizontes? Eu não sei o que é isto: mas a vida a bordo confirma toda a vocação de aventura espiritual que até aqui fora somente feitio poético; e estou certa de que seria mais feliz se já não voltasse para o destino da terra, se ficasse marinheira para o resto da vida, com este vento do mar na testa e as novas dimensões que o oceano ensina às pupilas que desejam ver? ${ }^{\text {I3 }}$

A temática da marinhagem, dos "descobrimentos" que ela permite, retornará em sua obra posterior, em verso e prosa. No poema "Beira-mar", de Mar absoluto, o eu-lírico diz:
Sou moradora das areias, de altas espumas: os navios passam pelas minhas janelas como o sangue nas minhas veias, como os peixinhos nos rios...
Não têm velas e têm velas; e o mar tem e não tem sereias; e eu navego e estou parada, vejo mundos e estou cega, porque isto é mal de família, ser de areia, de água, de ilha... E até sem barco navega quem para o mar foi fadada.
Deus te proteja, Cecília, que tudo é mar - e mais nada ${ }^{\mathrm{I}}$.

Vínculo entre o desejo de ser marinheira e as origens familiares que ganham contornos mais concretos nas crônicas sobre a Ilha do Nanja, fantasia em prosa-poética construída a partir de uma viagem, em novembro de I95I, à ilha de São Miguel, nos Açores, terra de origem da avó Jacintha, que a criou, como nesse fragmento de "Saudade da Ilha do Nanja": "Antigamente, eu quase não pensava na Ilha do Nanja; ou, melhor, não pensava nela com esta saudade de agora. Sabia-a no meio do mar, coberta de flores azuis, com estufas de ananases no lugar dos velhos laranjais dos meus avós”ז5.

Em II de outubro, Cecília revela sentimentos ambíguos em sua expectativa pelo desembarque em Lisboa no dia seguinte, quer descer à terra, mas preferiria continuar marinheira, e pergunta-se: "Por que os países não viajam conosco? Por que não se amarram as terras aos navios, para irmos andando sobre as águas, vendo, ao mesmo tempo, o encanto dos países que se escondem, imóveis, na rede

\footnotetext{
I3 Ibidem, p. I43-I44.

I4 Idem. Poesia completa. Rio de Janeiro: Nova Fronteira, 200I, p. 488-489.

I5 MEIRELES, Cecília et. al. Quadrante 2. 4.ed. Rio de Janeiro: Editora do Autor, I968, p. 64.
} 
dos paralelos e dos meridianos?”ㄷ. E, novamente, explicita o desejo de ser do mar: "Fenícios! Argonautas! Lusíadas! - mas por que não nasci marinheiro; por que não me deram ao mar?”ᄁ . A temática da marinhagem se vincula à da origem familiar, sua avó açoriana lhe contava histórias do mar e usava termos náuticos, como revela na crônica memorialista "Meus 'Orientes”:

Minha avó, que falava uma linguagem camoniana, costumava dizer, em certas oportunidades: “Cata, cata, que é viagem à Índia!”. Eu ainda não sabia do sentido náutico do verbo "catar": mas parecia-me que, com aquele estribilho, tudo andava mais depressa, como para uma urgente partida ${ }^{18}$.

Mas é no poema "Caronte", de Mar absoluto, que a marinhagem liga claramente o símbolo do infinito ao desejo de transcendência espiritual que seria, ao mesmo tempo, reencontro com as origens familiares, por isso a morte, por meio do barqueiro que leva as almas para a outra margem do rio, é figurada como amiga:
Caronte, juntos agora remaremos:
eu com a música, tu com os remos.
Meus pais, meus avós, meus irmãos, já também vieram, pelas tuas mãos.
Mas eu sempre fui a mais marinheira:
trata-me como tua companheira.
Fala-me das coisas que estão por aqui, das águas, das névoas, dos peixes, de ti. Que mundo tão suave! que barca tão calma! Meu corpo não viste: sou alma ${ }^{19}$.

Em I2 de outubro, o navio chega a Lisboa antes do amanhecer. Já às três da manhã, a poeta-marinheira está à espera para ver as primeiras luzes da cidade. Segue-se uma descrição impressionista das formas de Lisboa que vão aparecendo sob a luz, cujas palavras ganham perfeita correspondência nas ilustrações de Correia Dias ${ }^{20}$, em imagens em que predominam o verde e o amarelo e que sugerem paisagens urbanas $\mathrm{e}$ marinhas ainda a certa distância, sob a luz incompleta de um amanhecer inacabado:

- Este sol preguiçoso de Lisboa custa muitíssimo a aparecer!

E enquanto passam as vozes, e os olhos procuram descobrir os nomes da paisagem, e todos se apressam para o instante de uma visão definitiva, vão despertando as águas

\footnotetext{
I6 MEIRELES, Cecília. Diário de bordo, op. cit., 20I5, p. I57-I58.

I7 Ibidem, p. I59.

I8 Idem. O que se diz e o que se entende. 2.ed. Rio de Janeiro: Nova Fronteira, I980, p. 36.

I9 Idem. Poesia completa, op. cit., 200I, p. 5II-5I2.

20 In: MEIRELES, Cecília. Diário de bordo, op. cit., 20I5, p. I62-I64.
} 
do Tejo, vai-se tingindo o céu de cores tênues, uma luz de ouro muito leve embebe a distância, e colore a cidade, de suas casas superpostas, com manchas rosadas e brancas, amarelas, cinzentas, azuis.... ${ }^{21}$.

Esse olhar contemplativo para os traços da Lisboa, que ressurge ao amanhecer, permanecerá desperto na madrugada passada diante de uma janela em Amsterdã, à espera do retorno da luz e das formas da cidade, na crônica "Amor correspondido", de I953:

Pela madrugada, a cidade começou a voltar: delinearam-se as ruas, lá embaixo, muito longe... Ouvi ou imaginei campainhas de invisíveis cavalos, acolchoadas em névoa?

Regressaram os barcos, e sua sombra descia pela água dos canais, pouco a pouco cintilantes.

As paredes das casas foram reconstruídas, com suas janelas, e as janelas com suas cortinas arregaçadas sobre um jarro de flores ${ }^{22}$.

O desembarque em Lisboa sugere a imagem de um nascimento: "[...] Salto para terra. E vou indo como sonâmbula, para onde me vão levando - porque eu não sei nada, compreenderam? Eu sou um coração que vai cantando segundo o ritmo da vida que anda em redor..."23.

Entrega à descoberta desse mundo novo, e originário, para ela, semelhante a um nascimento, é impressão que reaparecerá também nos registros de uma viagem a Amsterdã na década de I950, cidade cuja diafaneidade da luz, que tudo parece desmaterializar, a fascina. Assim Cecília finaliza a crônica "Noite maternal", de I953, depois de descrever a casa holandesa que a hospeda, figurando o quarto como um útero ou um colo materno, a janela, os barcos atracados nos canais, como um convite à vida: "Mas a paz da rua chama-me para a janela. Mas o reflexo dos canais e o vulto dos barcos e a tranquilidade das casas são mais repousantes que todos os sonos. E com tua estrela contemplo a noite, Amesterdão"24.

Diário de bordo encanta como registro de um primeiro olhar sobre o oceano, uma primeira experiência de viagem ao exterior e de possibilidade de encontro concreto com a terra da ancestralidade, mas também revela a íntima correspondência entre os olhares de Cecília e de Fernando, separados tragicamente pelo suicídio dele ainda em I935, mesmo ano em que retornaram de Portugal. Além da qualidade da edição e do valor literário e artístico da obra, ela ainda revela ao leitor atento as primeiras visões e elaborações literárias de temáticas que aparecerão posteriormente na obra poética e nas crônicas de viagem de Cecília Meireles. Obra fundamental para a compreensão do olhar dessa poeta-marinheira.

2I MEIRELES, Cecília. Diário de bordo, op. cit., 20I5, p. I64.

22 Idem. Crônicas de viagem - 2, op. cit., I999, p. I45.

23 Idem. Diário de bordo, op. cit., 20I5, p. I66.

24 Idem. Crônicas de viagem - 2, op. cit., 1999, p. 150. 


\section{REFERÊNCIAS BIBLIOGRÁFICAS}

GOMBRICH, E. H. História da Arte. I6.ed. Tradução Álvaro Cabral. Rio de Janeiro: LTC Editores, I999.

MEIRELES, Cecília et. al. Quadrante 2. 4.ed. Rio de Janeiro: Editora do Autor, I968.

MEIRELES, Cecília. O que se diz e o que se entende. 2.ed. Rio de Janeiro: Nova Fronteira, I980.

. Crônicas de viagem - I. Rio de Janeiro: Nova Fronteira, I998.

. Crônicas de viagem - 2. Rio de Janeiro: Nova Fronteira, I999.

. Poesia completa. Rio de Janeiro: Nova Fronteira, 200I.

. Batuque, samba e macumba. São Paulo: Martins Fontes, 2003.

. Diário de bordo. Ilustrações de Fernando Correia Dias. São Paulo: Global, 2015.

. Artes populares. Rio de Janeiro: Ediouro, s.d.

MEIRELES, Cecília et. al. Quadrante 2. 4.ed. Rio de Janeiro: Editora do Autor, I968,

RENNER, Rolf Günter. Edward Hopper (I882-I967): transformaciones de lo real. Tradução Enrique Knörr.

Alemanha: Taschen, 2002. 